\title{
P I5-I5. Advocates' perspectives on community engagement in the HVTN 505
}

\author{
M Warren*, E Bass, C Feuer, K Fisher, D Grant and L Miller
}

Address: AIDS Vaccine Advocacy Coalition, New York, USA

* Corresponding author

from AIDS Vaccine 2009

Paris, France. 19-22 October 2009

Published: 22 October 2009

Retrovirology 2009, 6(Suppl 3):P2I6 doi:10.1 I86/1742-4690-6-S3-P216

This abstract is available from: http://www.retrovirology.com/content/6/S3/P2I6

(C) 2009 Warren et al; licensee BioMed Central Ltd.

\section{Background}

In September of 2007, the trial of Merck's MRK-Ad5 AIDS vaccine candidate came suddenly and unexpectedly to a halt. Results suggesting enhanced susceptibility to HIV infection in certain trial participants placed the planned PAVE 100 trial of the Vaccine Research Center's DNA prime/Ad5-vectored boost vaccine strategy into question. At the same time, the Step trial analysis suggested that some vaccines might have benefited from lower viral loads post infection. A year after Step ended, NIAID announced that it was considering a smaller trial of the VRC's strategy, which became HVTN 505 - no longer PAVE 100.

\section{Methods}

Since the Step results were announced, AVAC and its partners have engaged in numerous structured conversations with NIAID, its Vaccine Research Program, CABs and the broader community of HIV prevention advocates like AVAC who are not part of trial site communities. This work has provided a documented case history of how community engagement has functioned within the context of both the Step trial and proposed trials of the VRC candidate.

\section{Results}

The Step results brought an unprecedented dialogue between the trial sponsors and civil society. There was a high level of information and materials sharing and constructive dialogue around crafting messages that were accurate and moved the field ahead. This held true around PAVE 100 as well. But with the advent of 505, the gap has increased between the broader community and the trial sponsors, which has impeded community stakeholders from getting involved.

\section{Conclusion}

HVTN 505 will likely be one of the most complex trials to explain and in which to enroll participants, making the collaborative work that should be in place for any trial critically important. Community participation and engagement in Step made important progress toward integration into clinical trial development and support. The success of HVTN505 depends upon building and expanding upon that progress. 